\title{
Un curso de filosofía del Chile colonial: los Comentarios Acerca del alma de fray Juan de Fuica (1689)
}

\author{
ABEL ARAVENA ZAMORA \\ Universitat de Barcelona (España) \\ abel.aravena@hotmail.com
}

\begin{abstract}
Resumen
El siguiente artículo revisa brevemente diferentes aspectos de los Comentarios Acerca del alma, dictados por el franciscano chileno fray Juan de Fuica, en mayo de 1689, en el Colegio San Diego de Alcalá de Santiago de Chile. Presentamos, primero, una nota biográfica del fraile con información relativa a su trayectoria académica y administrativa dentro de la orden franciscana. Luego, analizamos en cinco categorías los aspectos fundamentales de este curso inédito: características generales, características del lenguaje, estructura, método de enseñanza y contenidos ad mentem Scoti. Creemos que con la edición de este testimonio exclusivo de la enseñanza filosófica de la época, visibilizamos el patrimonio filosófico colonial del país y, en consecuencia, llenamos una gran laguna en la historia de la filosofía chilena.

Palabras clave: Animástica, historia de la filosofía, escotismo, filosofía colonial, filosofía chilena, manuscrito filosófico.

\section{A philosophy course from colonial Chile: Juan de Fuica's "Commentaries On the Soul" (1689)}

\begin{abstract}
This article briefly reviews the different aspects of the Commentaries On the Soul, dictated in 1689 by Chilean Franciscan Friar Juan de Fuica at San Diego de Alcalá College, Santiago de Chile. First, we present a biographical note on the Friar with information concerning his academic and administrative career within the Franciscan order. Second, we analyze in five categories the fundamental aspects of this unreleased manuscript: general features, language features, structure, teaching method and ad mentem Scoti contents. We believe that with the edition of this exclusive testimony of philosophical teachings at that time, we give visibility to the colonial philosophical heritage of the country and, thereby, fill a gap in the bistory of Chilean philosophy.
\end{abstract}

Keywords: Animastics, bistory of philosophy, scotism, colonial philosophy, Chilean philosophy, philosophical manuscript.

Licenciado en Educación y Licenciado en Filosofía por la Universidad de Playa Ancha. Doctor en Filosofía por la Universitat de Barcelona. Es autor del libro Averroes y la facultad imaginativa (2012) y ha publicado los artículos "Manuscritos filosóficos coloniales conservados en el Archivo Nacional Histórico de Santiago de Chile" (2015), "El comercio librario y la transmisión de la filosofía a Hispanoamérica (siglos XVI al XVIII)" (2014), "Aristotelismo colonial: breves notas sobre su transmisión en el Virreinato del Perú de los siglos XVII y XVIII" (2013), "Aristóteles y la filosofía presocrática: anotaciones sobre el 'rescate' filosófico de sus predecesores” (2011).

Recibido: 9/Enero/2016 - Aceptado: 4/Marzo/2016 


\section{Introducción}

Los Comentarios a los tres libros Acerca del alma según la doctrina de nuestro Doctor Sutil Duns Escoto, Príncipe de los Teólogos [Commentaria in tres libros De anima ad mentem nostri Subtilis Doctoris Duns Scoti, Theologorum Principis] son el último de los comentarios que incluye el curso trienal (1687-1689) dictados por fray Juan de Fuica.

El curso completo lleva por título Commentaria phylosophica ad mentem Doctoris Subtilissimi Patris Fratris Joannis Duns Scoti Sacratissimi Ordinis Minorum et Theologorum Principis y actualmente se conserva en el Archivo Franciscano de Santiago de Chile. Este volumen reúne cinco comentarios ad mentem Scoti, dictados en dos de los centros de enseñanza que la orden mantenía en la ciudad en la época colonial: el Convento Grande de Santa María del Socorro y el Colegio San Diego de Alcalá. De acuerdo con los datos que hemos recogido, creemos que este curso trienal podría ser un esbozo para un eventual Manual de estudios de la provincia seráfica chilena (Medina, 1905: v. 1, CXXXVIII).

Los Comentarios Acerca del alma son producto del magisterio temprano del fraile, ya que fueron dictados cuando Fuica contaba con alrededor de treinta años. No obstante, constituyen un buen ejemplo de un curso introductorio destinado a familiarizar a los jóvenes frailes que continuarían con los estudios de teología.

En nuestra convicción de que este curso es un testimonio privilegiado de la tradición escotista en Chile y de la enseñanza filosófica de la época colonial, presentamos en este trabajo nuestra traducción al castellano de los pasajes estudiados y cuando es pertinente anotamos también la transcripción del texto latino. De este modo, pretendemos que los Comentarios Acerca del alma se transformen en una herramienta de investigación filosófica e histórica que permita rescatar y enriquecer el patrimonio filosófico colonial del país.

\section{Nota biográfica}

Fray Juan de Fuica de Huerta nació alrededor del año 1660 en el seno de una familia noble de la ciudad de La Serena, en la IV región de Chile, que se relaciona íntimamente con el desarrollo de la ciudad y con la historia del país.

El fraile fue hijo del Capitán don Gabriel de Fuica y de doña María de Huerta, ambos nacidos en La Serena. Por línea paterna, fue nieto de Mariana de Carvajal, natural de la misma ciudad, y del Maestre de Campo don Gabriel de Fuica (†1657), español natural de Bilbao, quien fue Alcalde ordinario, Provincial y Corregidor de la ciudad, llegando a ser Ma- 
yordomo mayor de la Cofradía de Nuestra Señora del Rosario y «dueño de un entierro perpetuo para sí y sus descendientes, en la capilla mayor del Convento de Santo Domingo; declarado Hermano y benefactor de la Orden, 1645». Asimismo, por línea materna paterna, fray Juan de Fuica fue bisnieto de Francisco de Aguirre, quien había llegado a Chile en 1540 junto a Pedro de Valdivia y participó en la fundación de las ciudades de Santiago (1541) y La Serena (1549) (Espejo, 1917: 111).

Según leemos en las declaraciones de los testigos en su toma de hábito, fechadas en mayo de 1676 (Cazanova, 1998: 168), Fuica descendía de una familia de cristianos viejos de la ciudad, que «no de moros ni infieles» (Informes de Novicios: 17v) y «no había cometido delitos que la ley prohibiera -como son-crímenes, hurtos u otros semejantes por los cuales deba ser castigado» (Informes de Novicios: 16).

Fue declarado Predicador en 1683 (Iturriaga, 2001: 48) y dos años más tarde fue instituido Confesor y designado Lector de regla y Maestro de estudiantes de Artes en el Convento Grande de Santa María del Socorro de la ciudad de Santiago (Iturriaga, 2001: 52). En abril de 1687 le encontramos aún en el mismo Convento con el cargo de Lector de Artes, como se indica en la portada general del libro que contiene los cinco Comentarios dictados por el fraile, donde detalla su condición de "antiguo Maestro de estudiantes"1.

Durante 1688 debió ser trasladado al colegio San Diego de Alcalá que la orden mantenía en Santiago, pues en el título de los comentarios a la Physica, fechados en noviembre de ese año, aparece ya enseñando en dicha institución ${ }^{2}$. Sin embargo, es en junio de 1689 cuando aparece oficialmente designado como Lector de Artes (Iturriaga, 2001: 62). Así se indica en las portadas de los dos últimos Comentarios: Acerca de la generación y la corrupión y Acerca del alma. En ambas se lee: Profesor de la cátedra de Artes, 14 de mayo de $1689^{3}$. Meses después, en octubre de ese mismo año, fue designado Lector de moral y Maestro de estudiantes teólogos en el mismo colegio (Iturriaga, 2001: 68).

Un par de años más tarde, el fraile fue trasladado a la ciudad de Penco. Allí permaneció algunos años, probablemente entre 1691 y 1695-6, desempeñándose en diferentes cargos: Lector de nona, Maestro de estudiantes, Lector de moral, Predicador mayor y Rector de la Tercera Orden en el Convento (Iturriaga, 2001: 74, 79, 85, 89). Cabe señalar que unos

1 "Olim Magistrum studentium, nunc autem in Magno Beatae Mariae de Succursu Civitatis Sancti Jacobi Artium Cathedrae Moderatorem”.

2 "Olim Magistrum Studentium, nunc autem in Chilleno Sancti Didaci de Alcalá Collegio Artium Cathedrae Moderatorem".

3 “...et in hoc Sancti Didaci de Alcala Collegio Artium Cathedrae Professorem". 
veinte años después, en 1710, el franciscano vuelve nuevamente a esta ciudad, esta vez como Guardián del Convento (Ramírez, 1992: 8).

En 1697 el fraile vuelve al Colegio San Diego de Alcalá de Santiago como Lector vespertino - moral (Iturriaga, 2001: 103, 109), y dos años después es elegido Definidor y designado Lector vespertino - regla y Lector de mística en el mismo colegio (Iturriaga, 2001: 113, 117).

Ya en el siglo XVIII, en marzo de 1707, el fraile fue declarado Lector Jubilado (Ramírez, 1992: 4), lo que lo hacía merecedor de la jubilación al haber cumplido con el requisito de enseñar durante quince años como profesor de una cátedra.

Entre octubre de 1724 y 1726 fray Juan de Fuica fue Guardián y Rector del Colegio San Diego de Alcalá (Actas del Definitorio: 286, 305r) y en febrero de 1728 fue nombrado Presidente de la comisión encargada de redactar las nuevas leyes particulares para dicha institución (Ramírez, 1992: 33-34). Este último hecho, importantísimo para entender su relevancia dentro de la orden franciscana, derivó probablemente en la redacción de las segundas Constituciones del colegio San Diego (1732) (Medina, 1905: v. 1, CCCLVI).

Asimismo, durante un período de doce años, entre 1721 y 1733, se desempeñó como Examinador de predicadores, confesores y audientium (Actas del Definitorio: 254, 265, 349r, 351) y, paralelamente, entre 1728 y 1729, fue el Cronologus Provinciae (Actas del Definitorio: 322r, 335), vale decir, el religioso responsable de compilar y redactar las crónicas o la historia cronológica de un convento de una Provincia Seráfica (Ramírez, 1993: 64).

\section{Características generales de los Comentarios Acerca del alma}

Como ya hemos avanzado, el libro contiene un total de cinco comentarios iuxta mentem Scoti de las obras de Aristóteles, dictados por el fraile en la cátedra de Artes en el Convento del Socorro y en el Colegio San Diego de Alcalá (Iturriaga, 1990a). Todos los textos de este curso trienal fueron copiados por fray Francisco de Morales, quien firma con su nombre y se identifica como alumno de fray Juan de Fuica en las portadas de cada uno de los comentarios.

El curso completo se ordena del siguiente modo:

1. Commentaria in Universam Aristotelis Logicam una cum distinctionibus et quaestionibus iuxta mentem et doctrinam Doctoris Subtilis Ioannis Duns Scoti Theologorum Facile Principis. [Convento del Socorro,1687].

2. Commentaria in Universam Aristotelis Metaphysicam una cum distinctionibus et quaestionibus iuxta mentem et doctrinam nostri 
Subtilissimi Doctoris Fratris Ioannis Duns Scoti Theologorum Facile Principis. [Convento del Socorro, 1687].

3. Commentaria in octo libros Physicorum Aristotelis Stagiritae una cum distinctionibus et quaestionibus iuxta mentem et doctrinam nostri Subtilissimi Doctoris Fratris Ioannis Duns Scoti Theologorum Facile Principis. [Colegio San Diego de Alcalá, 1688].

4. Commentaria in duos libros Aristotelis De generatione et corruptione secundum mentem nostri Doctoris Subtilis Fratris Ioannis Duns Scoti Theologorum Principis. [Colegio San Diego de Alcalá, 1689].

5. Commentaria in tres libros De anima ad mentem nostri Subtilis Doctoris Duns Scoti, Theologorum Principis. [Colegio San Diego de Alcalá, 1689].

Todos los textos están escritos en latín, en papel, con tinta ferrogálica, a una columna y entre 33 - 37 líneas por hoja. El libro no presenta encuadernación y tiene unas dimensiones de 20 x $15 \mathrm{~cm}$ y 592 páginas. Algunas de las hojas han sido numeradas posteriormente con lápiz de carbón.

El lomo del volumen presenta las costuras a la vista y probablemente conserva las cabezadas y los nervios originales. Se evidencian intervenciones posteriores en el libro: compensaciones de papel impreso entre las costuras y algunos refuerzos de tela. La portada se observa con manchas de humedad y suciedad, con rasgados y zonas faltantes en el extremo inferior. El cuerpo del libro se encuentra ligeramente deformado y con ondulaciones.

En general, los títulos de las distinciones aparecen con letras capitales y la primera letra adornada con dibujos. Asimismo, los títulos de las cuestiones y distinciones suelen adelantarse al finalizar la cuestión o distinción precedente.

\section{Características del lenguaje en los Comentarios Acerca del alma}

En los Comentarios Acerca del alma se encuentran algunas particularidades de la lengua que conllevan un importante esfuerzo para comprender cabalmente el texto. Pues, el latín colonial expresado en el curso de fray Juan de Fuica proviene, como el de todas las colonias hispanoamericanas, del latín cultivado en España en el tardío Medioevo. Por ello, posee las características propias de este estado de la evolución de la lengua y dista mucho de la norma clásica. De manera que no puede asociarse exclusivamente a las características del latín medieval, ya que se trata de una lengua en la que se fusionan diferentes vertientes culturales europeas e hispanoamericanas. 
En efecto, encontramos, por una parte, los caracteres fundamentales del latín eclesiástico ${ }^{4}$, desarrollado sobre la base del latín vulgar ${ }^{5}$ e inclinado a la literalidad y la adopción de helenismos, neologismos y adaptaciones de la lengua (Palmer, 1974: 187-191). Este hecho no resulta extraño si recordamos que los principales centros de estudios de la época colonial eran aquellos mantenidos por las distintas órdenes religiosas, especialmente jesuitas, dominicos y franciscanos. Y, por otra parte, hallamos las tendencias del neolatín y del latín de los humanistas, orientadas hacia el purismo y la corrección, inclinación que exitosamente se cultivaba en Salamanca y otras universidades españolas ya desde el siglo XVI.

Además, podemos agregar otro elemento que caracteriza de manera inconfundible al latín colonial: su contacto con el castellano hablado en América. Como puede apreciarse en nuestros Comentarios, se trata de una lengua con caracteres muy peculiares y que refleja también, de alguna manera, la particular naturaleza del fenómeno del mestizaje hispanoamericano (Nava, 1997: 187; Tovar, 1970: 101-125).

En este sentido, podemos centrar el análisis de nuestro texto, por un lado, en la frecuencia de las faltas cometidas y, por otro, en los excesos de corrección o hipercorrecciones, es decir, las transgresiones de las normas literarias, pues son estos fenómenos los que dan cuenta de las particularidades lingüísticas. De tal modo, podemos estructurar estos aspectos en cuatro categorías, a saber: mudanzas y errores ortográficos, mudanzas semánticas y léxico empleado.

En cuanto a las mudanzas ortográficas, podemos apreciar que el lenguaje presenta características derivadas de la ortografía latina expresada en la época (Väänänen, 2003: 42-64; Palmer, 1974: 161-175). En primer lugar, el caso más frecuente es la supresión de la doble consonante, como podemos ver en: disimilitudo (p. 5), aducit (p. 9), quatuor (pp. 11 y 30), eflunt (p. 13), comensurationibus, comensurationem y difunditur (p. 19), remititur (p. 20), efluit (p. 23), pupila (p. 29), molities (p. 30), conaturaliter (p. 33), comensurationem (p. 34), quiditas (p. 39), exprasiva (p. 43), gramaticaliter (p. 45) y rederet (p. 46). También observamos con frecuencia la tendencia a la hipercorrección al duplicar consonantes, por ejemplo: deffectum (p. 6), deffectu (p. 11), summuntur (p. 13), defficit (p. 24), decissum (p. 35) y defficeret (p. 41). Y, por último, apreciamos la grafía del diptongo -ae por $-e$, como vemos en: panne (p. 12) e illesum (p. 31).

4 Sobre el latín cristiano, véase Palmer (1974), capítulo VII; Herrero (1965), capítulo IX.

5 Respecto de los debates en torno al latín vulgar, véase Väänänen (2003: 31-35) y desde una perspectiva más general Palmer (1974), capítulo VI; Herrero (1965), capítulo VII. 
Pueden observarse además algunos errores ortográficos derivados del contacto del latín de aquel entonces con el castellano hablado de América, que dio origen al 'seseo' del castellano hispanoamericano. De este modo, constatamos que el dictado no observaba la diferenciación peninsular entre la pronunciación de la $/ c /$, la $/ s /$ y la $/ z /$. En esta categoría es justamente donde encontramos el mayor número global de errores, como apreciamos en: noce, asingit y discertationes (p. 3), sencitive y excecutionis (p. 6), confisiant (p. 7), prasipue (pp. 8 y 21), cruze (p. 9), cresere y prosedat (p. 11), consilium (p. 12), assendit (p. 13), dicipulis (p. 15), sitato (p. 17), creserent (p. 20), phycisi (p. 21), abssisa (p. 24), seleberrima (p. 25), persipitur (p. 26), recidet (p. 29), persipiens (p. 30), serebrum, serebro, concupisibilis, consilio e Inosentio (p. 31), consedimus (p. 32), sincibilibus (p. 37), plaucibilior (p. 40), sitatis (p. 42), confuce (p. 44) y resentiores (p. 45).

Derivado de lo anterior encontramos también el frecuente error en las combinaciones y terminaciones -tio(a) por -cio(a) o -sio(a), como por ejemplo en: essensialiter (p. 13), intensionale (p. 28), proporcionatum y proporsionatum (p. 38), intensionali (p. 42) e inditium (p. 47). Observamos, además, la tendencia a la hipercorrección de estas mismas terminaciones, como vemos repetido en controvertia (pp. 11, 31 y 38). De la misma mane$\mathrm{ra}$, frecuente y derivado de la particular pronunciación hispanoamericana es el error que aparece de la indiferenciación entre la / $v /$ y la / $b /$, como puede verse en: vilis (p. 11), exhivitionem (p. 13), Abisena (p. 24), suabitas (p. 30), elebet y adiubet (p. 35) y elebatione (p. 38).

Apreciamos asimismo con frecuencia algunos otros errores ortográficos que a continuación detallamos. La supresión o inclusión errónea de la grafía ' $b$ ', como en: authoritatibus (p. 8), melancolia y colera (p. 11), sacari (p. 26), christalino (p. 29) y ethimologia (p. 42). También la utilización de la 'y' con valor vocálico, especialmente frecuente en el caso de los helenismos, como por ejemplo en: phyllosophari y phyllosophice [sic] (p. 3), phyllosophicas [sic] (p. 7), Phyllosopho [sic] (pp. 11 y 12), Phyllosophus [sic] (p. 21) y phyllosophos [sic] (p. 36). Del mismo modo, hallamos la sustitución de $-f$ en lugar de $-p h$, como en: flema (p. 11) y elefantis (p. 23); la sustitución de $-\mathrm{m}$ por $-\mathrm{n}$ : quanvis (pp. 12 y 42), quocunque (p. 39), saltin (p. 41), circunfertur (p. 42) y Utrunque (p. 47); el error en las combinaciones $-x c$. exellentiorum (p. 5) y exellentior (p. 31) y -mp: sumtionem (p. 12); y, finalmente, vemos la sustitución de $-c$ por $-q$, como por ejemplo en: loquutionem (p. 43) y loqutionis (p. 44).

Es de destacar también la recurrente utilización de adjetivos con la formación de carácter popular en -bilis (Palmer, 1974: 190), por ejemplo en: possibilis (pp. 8, 22, 25, 34, 35, 36, 37 y 38), sensibilis (pp. 11, 26, 28, 35 y 39), vegetabilis (pp. 11, 19 y 21), divisibilis (pp. 23 у 24), intelligibilis (pp. 35 y 36), assignabilis (p. 8), unibilis (p. 25), concupiscibilis (p. 31), irascibilis (p. 
31), educibilis (p. 33), passibilis (p. 35), repraesentabilis (p. 39), impossibilis (p. 46) y rationabilis (p. 48). Encontramos además empleados con mucha frecuencia los adverbios en -ter (Palmer, 1974: 190) como a lo largo del texto vemos en: vitaliter, formaliter, realiter, naturaliter, accidentaliter, essentialiter, specialiter, taliter y materialiter.

Por otro lado, otra característica propia del latín de esta época son las mudanzas semánticas que alejan a los pronombres de su significado y, en consecuencia, del régimen correcto (Väänänen, 2003: 197-208; Palmer, 1974: 167, 191; Herrero, 1965: 139-140). Este fenómeno es un distintivo propio del latín eclesiástico y proviene del latín vulgar. En nuestro texto se puede observar cómo el significado de los demostrativos latinos se acerca más al significado que tuvo finalmente en castellano. Lo anterior lo apreciamos repetidamente en el caso de iste, el que llega a compartir el carácter de deíctico con hic, como por ejemplo en: “...nec reduci potest bic effectus ad causas universales, quia iste secundum diversas applicationes diversos effectus producunt, ut patet..." (p. 8); "Si vero loquamur metaphysice secundum quod proscindit gradus genericus viventis a vegetativo, sensitivo et rationali, ista tres anima non distingunntur ut tres forma physica..." (p. 13); ...ille "cuius est omnia facere', iste'cuius est omnia fieri'..." (p. 35) у "...multa a nobis intelliguntur quorum species intelligibiles non habemus: ergo ista non sunt necessaria" (p. 37).

En menor medida, aunque también presente en los Comentarios, encontramos el uso de la preposición «in» asociada mayormente al caso acusativo que al ablativo (Väänänen, 2003: 182; Palmer, 1974: 170; Herrero, 1965: 141). Con respecto a la utilización de los demás casos, se aprecia en general una tendencia a la corrección.

Destacan además las particularidades de la subordinación substantiva, donde resalta la notoria ausencia de la estructura de acusativo con infinitivo, reemplazada por la construcción de quod + indicativo (Palmer, 1974: 171-172, 191), como se aprecia, por ejemplo, en: «Respondetur ad argumentum, quod bac forma corporeitatis datur propter corpus organicum, quod non causatur ab anima, cum prasupponatur pro aliqua prioritate naturce ad productionem illius» (p. 10). Destacan también los hispanismos en algunas construcciones como non potest esse (p. 8, 43 y 48), que son absolutamente ajenas al estilo clásico.

Por último, es en el léxico empleado por el fraile en donde se aprecian con mayor claridad, como puede comprenderse, la influencia del latín eclesiástico. Se manifiesta por la presencia tanto de términos religiosos como de helenismos y neologismos derivados del metalenguaje filosófico griego, que habían sido adaptados al latín desde épocas muy anteriores y actualizados al revalorizarse los estudios aristotélicos en el tardío Medioevo (Palmer, 1974: 189-190; Herrero, 1965: 175-178). Finalmente, es preciso indicar que estas particularidades propias del metalenguaje 
filosófico de la metafísica limitan las expresiones del habla vulgar que pudiesen indicar alguna tendencia específica en el texto de los Comentarios.

\section{Estructura de los Comentarios Acerca del alma}

En el curso destaca el afán pedagógico del fraile por organizar los contenidos de una manera introductoria, pero igualmente de una forma clara, inteligible y-según nos dice- en un estilo propio.

Es de notar, por una parte, la similitud del curso con el plan del De anima de Suárez, el que a su vez se asemeja a la exposición de Santo Tomás del estudio del alma humana en la Suma Teológica (pars I, q. LXXV$\mathrm{XC}$ ). Y, por otra, que la estructura del curso de Fuica se acerca más al tratamiento que hace el Estagirita de los contenidos animásticos por sobre aquella que adopta el Doctor Sutil. Si bien el franciscano de La Serena no aborda las materias estudiadas en el libro primero por el Filósofo, incluye, en cambio, el estudio de temáticas propias de la psicología cristiana, ajenas totalmente a las doctrinas aristotélicas. No obstante, en términos generales, el curso organiza sus contenidos de un modo que no hemos visto en ninguno de los otros cursos animásticos de la época que se conservan en el país y que hemos revisado (Aravena Zamora, 2015).

Siguiendo la tradición del sistema medieval, los Comentarios Acerca del alma del franciscano chileno abarcan casi las últimas cincuenta páginas del libro y están organizados en siete distinciones de diferente extensión que, a su vez, contienen las cuestiones en las que se presentan y desarrollan los argumentos respectivos. Las distinciones más breves -la segunda, tercera y quinta- incluyen dos cuestiones, mientras que la más extensa $-\mathrm{y}$ la última del curso- contiene once cuestiones.

De las veintitrés Quaestiones super secundum et tertium de anima de Duns Escoto, en este curso del fraile de La Serena se desarrollan doctrinalmente veintidós de ellas, con excepción de la cuestión once, aunque no se conservan los títulos originales utilizados por el Doctor Sutil.

Los Comentarios Acerca del alma de fray Juan de Fuica incluyen las siguientes distinciones:

1) Sobre el alma en general.

2) Sobre las potencias del alma en general.

3) Sobre la esencia y potencias del alma vegetativa.

4) Sobre el alma sensitiva y sus potencias en general.

5) Sobre los sentidos internos y externos.

6) Sobre el alma racional.

7) Sobre la potencia intelectiva. 


\section{Método de enseñanza}

El curso de fray Juan de Fuica constituye un testimonio privilegiado de la corriente escotista en el Chile del siglo XVII y nos brinda, además, la posibilidad de conocer de primera mano las características de la enseñanza filosófica de la época colonial (Guerrero Troncoso, 2014; Iturriaga, 1990b).

La obra da cuenta de los conocimientos filosóficos generales del fraile, ya que refleja que estaba al tanto de los temas fundamentales de los grandes pensadores escolásticos, así como de las disputas y controversias teóricas de sus contemporáneos -sobre todo españoles- acerca de determinados conceptos filosóficos y teológicos centrales.

En este sentido, vemos que recurre al método escolástico tradicional al presentar cada vez el tema a estudiar y las principales enseñanzas de las diferentes escuelas al respecto. Y luego, valiéndose fundamentalmente de las doctrinas aristotélicas, del Sutil y también de otras autoridades filosóficas, expone y explica en cada caso las sentencias verdaderas sobre el objeto de estudio respectivo.

Así, por ejemplo, al abordar en la quinta distinción el estudio de los cinco sentidos externos, los únicos evidentes en la experiencia, fray Juan de Fuica nos recomienda revisar las ideas de Galeno y Aristóteles en los escritos de los franciscanos Juan Poncio y Juan Merinero López.

De igual manera, hallamos que recurre a distintas autoridades filosóficas al abordar los aspectos biológicos vinculados con el alma sensitiva. En este sentido, al estudiar si el alma sensitiva es divisible, el fraile se apoya en los testimonios de Averrores y Avicena [«...el Comentador informa haber visto un carnero avanzado con la cabeza cortada y Avicena, a un toro caminando con el corazón extraído» (De Fuica, 1689: 24)], para concluir que una parte cortada del cuerpo sólo vive momentáneamente.

Si bien el franciscano de La Serena sigue las enseñanzas de Aristóteles a través de la interpretación escotista, es capaz de distanciarse de la teoría cardiocéntrica del Estagirita y seguir a Galeno al considerar al cerebro -y no al corazón- como el órgano del sentido interno y centro fundamental de las operaciones intelectuales (De Fuica, 1689: 31). Y aunque no hallamos en el texto otro ejemplo similar que nos permita generalizar este distanciamiento, no podemos perder de vista que en tiempos del fraile las ciencias experimentales -auxiliares de la psicologíano habían sido aún introducidas en las colonias hispanoamericanas.

Por otro lado, al estudiar ya el alma racional, encontramos que Fuica recurre a la autoridad de San Agustín para exponer la concepción del verbo mental. Al respecto enseña: «Este verbo creado [verbo mental] es el representante del Verbo Divino, como dice Agustín, puesto que en 
nuestra mente resplandece la imagen de la Santísima Trinidad» (De Fuica, 1689: 43).

Más adelante, al estudiar el intelecto agente, en la séptima y última distinción, el fraile concluye siguiendo a Aristóteles y expresamente en contra de dos teólogos: el dominico francés Guillaume Durando y el jesuita español Pedro Hurtado de Mendoza (De Fuica, 1689: 35). En la cuestión acerca de si Dios puede producir la intelección sin la concurrencia del intelecto, vemos que concluye afirmativamente oponiéndose a los teólogos jesuitas españoles Gabriel Vásquez y Luis de Molina, al teólogo cisterciense español Pedro de Lorca, al teólogo dominico español Luis de Montesinos, al teólogo dominico francés Jean Capréolus y al teólogo dominico italiano Francis Silvester de Ferrara (De Fuica, 1689: 45).

A lo largo del curso, el fraile recurre a diferentes autoridades franciscanas para presentar la enseñanza más verdadera. Así, por ejemplo, para explicar el concepto de forma de corporeidad (forma corporeitatis), cuyo detalle revisaremos en al apartado siguiente, recurre a Antonio Andrés, Juan Basolius, Juan de Rada, Juan Merinero López, el Padre Poncio y Alonso Briceño (De Fuica, 1689: 8). En este mismo sentido, en la última cuestión del curso, el fraile también hace alusión a diferentes autoridades de la orden franciscana (San Buenaventura, Alonso Briceño, Duns Escoto y Diego de Humanzoro) para concluir que la ciencia, la fe y la opinión puedan darse en el mismo intelecto respecto del mismo objeto (De Fuica, 1689: 48).

Destaca también el respeto demostrado por el fraile chileno hacia la auctoritas de los antiguos, sin hacer una diferenciación expresa entre autores cristianos o paganos. De esta manera, encontramos en el texto referencias a autoridades tan diversas como Aristóteles, Galeno, San Agustín, Santo Tomás, Avicena, Averroes y Escoto. No obstante, es el Estagirita el único autor clásico de la filosofía griega citado por Fuica, quien, en cambio, apoya alguna de sus conclusiones en autoridades de la Biblia, en los Santos Padres y en Cánones Conciliares (específicamente Letrán y Trento), como puede verse al discutir sobre la naturaleza e inmortalidad del alma racional (De Fuica, 1689: 31-34).

Por último, en cuanto a la frecuencia de las referencias que hallamos en el curso, podemos indicar que el autor más citado es, naturalmente, Duns Escoto y la Opus Oxoniense. Cabe destacar que Fuica no nombra expresamente esta obra, pero sí indica con precisión la ubicación de los pasajes respectivos. Luego viene Aristóteles, de quien el fraile se refiere a muchas de sus obras, sobre todo aquellas que estudian temas físicos y metafísicos (De anima, De partibus animalium, Metaphysica, De generatione et corruptione, De longitudine et brevitate vitae, De somno et vigilia, Ethica, De generatione animalium). Después encontramos las referencias a Santo To- 
más y la Summa Theologiae, la que tampoco es expresamente nombrada por el fraile y, finalmente, hallamos las referencias a San Agustín (De trinitate y De civitate Dei).

\section{Contenidos ad mentem Scoti}

El contenido de los Comentarios Acerca del alma manifiesta un marcado interés por la psicología racional, lo que es característico de la enseñanza escolástica. En ellos, el fraile expone y estudia los temas que son ya clásicos desde Aristóteles: la esencia y las potencias del alma, los actos y los objetos, los hábitos, los sentidos, la inmortalidad y espiritualidad del alma, y la naturaleza del intelecto. Además, como hemos señalado, incluye el estudio de temas propios de la psicología cristiana.

En la exposición del franciscano chileno predomina así una perspectiva psicológica por sobre un acercamiento biológico a los contenidos como el que hemos constatado, por ejemplo, en los tratados de Merinero, Poncio y Rada-, el que según el fraile es «de utilidad más bien para los Médicos que para los Animásticos» (De Fuica, 1689: 20). Por ello, el mismo Fuica recomienda a quienes se interesen por conocer con una mayor profundidad acerca de aspectos biológicos que recurran a los escritos de Merinero, Poncio o Galeno ${ }^{6}$ (De Fuica, 1689: 30).

En el preludio de los Comentarios, fray Juan de Fuica caracteriza el objeto de estudio del curso: la animástica. Explica que esta disciplina «es absolutamente especulativa, [y] tiene como objeto total el alma en general, en la medida que comprehende al alma vegetativa y a la racional» (De Fuica, 1689: 3).

Luego, el fraile de La Serena presenta expresamente el legado aristotélico. En la primera distinción del curso (De Fuica, 1689: 4), sobre el alma en general, adopta y explicita dos definiciones del alma transmitidas por el Filósofo. Primero, enseña que «el alma es el acto primero de un cuerpo natural orgánico que tiene vida en potencia» (De an. II, 1, 412a27). Y después indica que «el alma es aquello por lo que primariamente vivimos, sentimos, nos movemos de lugar e inteligimos» (De an. II, 2, 414a12-13).

Del mismo modo, algunas de las más importantes doctrinas escotistas se desarrollan en el curso del fraile chileno, entre las que podemos destacar: la distinción lógico-formal ex natura rei, que permite explicar que

6 Algunas de las obras de estos autores se encontraban en el Convento Grande de San Francisco, según consta en el inventario de sus libros (1799). Allí se reunieron las obras que durante más de un siglo albergó la biblioteca del Colegio San Diego de Alcalá y que podemos suponer que fray Juan de Fuica conoció. 
la unidad de una cosa $-\mathrm{y}$, por ello, el alma- contiene una pluralidad de formas distintas formalmente; la noción de esse obiectivum y la teoría de las causas parciales concurrentes, que explican y fundamentan el papel de intelecto y de las especies inteligibles en la doctrina del conocimiento escotista; $y$, por último, la noción de forma de corporeidad (forma corporeitatis), que es la forma orgánica del cuerpo. Sin embargo, dada la naturaleza de este trabajo, revisaremos aquí brevemente sólo ésta última $\mathrm{y}$ algunos aspectos relativos al intelecto.

La noción de forma de corporeidad es un concepto fundamental para entender la organización substancial de los cuerpos y un elemento clave en la doctrina metafísica y psicológica del Sutil. Fray Juan de Fuica escribe a modo de introducción sobre este tema: "Esta cuestión es bastante célebre entre las cuestiones filosóficas" (De Fuica, 1689: 7), y seguidamente desarrolla con detención dicha noción, su diferencia con el alma y la relación de aquella con el cuerpo de un ser viviente.

Así, encontramos que en la primera distinción anota: "La segunda y verdadera sentencia enseña que en todos los seres vivientes, además del alma se da una forma de corporeidad substancial, de donde proviene el cuerpo orgánico que es per se potencia en la composición de la forma suprema de los seres vivos" (De Fuica, 1689: 8). Argumenta que "la forma orgánica o de corporeidad no es específica, completa el ser específico y acabado de la cosa, puesto que de ella y la materia prima resulta un compuesto substancial incompleto, que es per se potencia respecto de la forma última de los seres vivos" (De Fuica, 1689: 7). Fuica agrega que al ser dirigida por la naturaleza, en tanto algo potencial respecto del alma, la forma de corporeidad es diversificada esencialmente según la distinción esencial del alma, a la que se ordena per se.

Vemos que la exposición del fraile chileno es coherente con las doctrinas psicológicas de Escoto, pues según éste la forma de corporeidad antecede natural o lógicamente -y no de una manera temporal- a la llegada simultánea de las almas intelectiva, vegetativa y sensitiva, que son creadas e infundidas inmediatamente por Dios.

Desde esta perspectiva, la forma de corporeidad da a la materia el ser corpóreo, informa sus elementos materiales, compone y dispone junto con la materia al cuerpo, que entonces queda apto para la recepción del alma intelectiva. Por ello, la forma de corporeidad sólo es una forma disponente e imperfecta o incompleta, pues es completada y perfeccionada por el alma intelectiva que se añade. Esta última es privativa del ser humano y perfecciona completamente al cuerpo, siendo así su propia forma constitutiva, a diferencia de la forma de corporeidad que sólo dispone, perfecciona y domina el compuesto materia-forma. 
Del mismo modo, la forma de corporeidad, al ser una forma imperfecta, permanece por sí sola en el cuerpo después de la muerte de un ser vivo, aunque no puede dominar sobre aquel por demasiado tiempo, por lo que un cadáver pronto se disuelve en sus propios elementos. Por esta razón, un cadáver no es una entidad en el sentido pleno del término. No obstante, de aquí se deriva el problema de si, en él, la forma de corporeidad está en el mismo estado que cuando estaba incluida bajo la forma de la totalidad animada.

De acuerdo con lo anterior, se sigue que la forma de corporeidad difiere realmente del alma, puesto que sólo la dispone y permanece en el compuesto, mientras que el alma es separada del cuerpo por la muerte. Respecto a esto, hallamos que el fraile de La Serena escribe acerca del cuerpo de Cristo:

...era el mismo el cuerpo de Cristo en el útero de la virgen, colgado en la cruz, el que yació en el sepulcro y el que resucitó: por tanto, era el mismo el cuerpo de Cristo muerto y vivo, en aquel momento y de tal modo. Pero, en el supuesto que no se de la forma de corporeidad del cuerpo conservado después de la muerte de Cristo el Señor, esto no sería verdad (De Fuica, 1689: 9).

Fray Juan de Fuica señala también el error de Santo Tomás y sus discípulos al afirmar que la razón del cuerpo orgánico proviene del alma (Summa Theologiae I, q. 76, art. 4) y no de la forma de corporeidad y, en cambio, -y como ya hemos adelantado en la sección anterior- declara seguir en esto al Sutil y a otros autores de la tradición escotista: Andrés, Basolius, Rada, Briceño, Merinero López y el Padre Poncio (De Fuica, 1689: 8).

En este contexto, explica la relación que se da entre la forma de corporeidad y la concepción de un ser vivo, descartando de plano la intervención de cualquier tipo de semen en el proceso. El fraile indica que la causa productora de la forma de corporeidad en los seres vivientes que son concebidos por una madre es el cuerpo orgánico de ella, que introduce una forma semejante en la materia del semen. En cambio, en los seres vivientes que no son concebidos por una madre, la causa eficiente de la forma de corporeidad es Dios y las demás causas universales (De Fuica, 1689: 8).

Por otra parte, en cuanto a la doctrina del conocimiento y el rol del intelecto en este proceso, hallamos también que el fraile de La Serena sigue la interpretación escotista de las enseñanzas de Aristóteles. En este contexto, valiéndose de las propias palabras del Estagirita (De an. III, 5, 430a14-15) según nos dice, adopta la distinción entre el intelecto agente y 
el intelecto paciente o posible: "aquel, que es capaz de hacer todas las cosas, y éste, que es capaz de llegar a ser todas las cosas" (De Fuica, 1689:35).

Fray Juan de Fuica enseña que es necesaria en el alma alguna facultad espiritual que cause junto al fantasma la especie inteligible, puesto que ésta no puede provenir del objeto material ni tampoco exclusivamente del fantasma. Por ello, explica que el intelecto agente "es la facultad espiritual que abstrae de los fantasmas las especies inteligibles hacia la fecundidad del intelecto posible" (De Fuica, 1689: 35). De manera que la función del intelecto agente "es iluminar por sí mismo inmediatamente el fantasma, puesto que asistiéndole concurre con aquello efectivo para proveer las especies inteligibles, por las que el intelecto posible es fecundado en la intelección" (De Fuica, 1689: 35).

Igualmente, en este mismo ámbito, encontramos que en el curso se desarrollan algunas cuestiones que son propias del pensamiento franciscano, como por ejemplo, si el asentimiento y el disentimiento -y también el amor y el odio- pueden estar por disposición divina en el mismo intelecto en torno al mismo objeto. El fraile chileno enseña que la omnipotencia divina (potentia absoluta Dei) hace posible dichas cosas y, a causa de ello, cualidades completamente opuestas pueden padecerse juntamente en un mismo sujeto (Saranyana, 2011: 356).

Por último, quisiéramos destacar la matizada figura de Aristóteles que el fraile presenta en el curso. Pues, por una parte, hallamos al Aristóteles de la tradición clásica, expresado en la concepción del alma y en la división de sus facultades que sustentan todas las enseñanzas. Pero, por otra parte, encontramos que interpreta con marcados tintes teológicos las doctrinas del Estagirita. En este sentido, al estudiar la cuestión de si el alma es creada por el semen, fray Juan de Fuica enseña que para los católicos es evidente que Dios crea el alma intelectiva, "lo que también ha notado Aristóteles cuando dice 'el intelecto llega desde fuera"' (De Fuica, 1689: 22).

\section{Conclusiones}

Los Comentarios Acerca del alma del franciscano chileno fray Juan de Fuica constituyen un testimonio privilegiado de la tradición escotista nacional de finales del siglo XVII y, además, dan cuenta de la enseñanza filosófica de la época colonial.

El manuscrito del fraile de La Serena constituye el curso de animástica de autor chileno más antiguo del que tenemos noticia. Cabe señalar que es casi cincuenta años posterior a las Celebriores controversiae in Primum Sententiarum Ioannis Scoti (Madrid, 1638 y 1642), del también franciscano 
chileno Alonso Briceño (ca1587-ca1668), quien -como hemos visto- es nombrado como una autoridad doctrinal franciscana.

En los Comentarios, se exponen los contenidos animásticos característicos de la enseñanza escolástica ad mentem Scoti, los que se corresponden con aquellos propios de la psicología racional. Si bien el fraile no aborda las materias estudiadas en el libro primero por el Filósofo, incluye, en cambio, el estudio de temáticas propias de la psicología cristiana, ajenas completamente a las doctrinas aristotélicas.

Aunque la fecha de redacción del curso (1689) indicaría que en él se expone una mentalidad juvenil, propia de los inicios del magisterio del fraile, creemos que los Comentarios son un buen ejemplo de un curso introductorio para los frailes que posteriormente continuarían con los estudios teológicos. En ellos queda constancia de que el franciscano chileno estaba al tanto de los temas fundamentales de los grandes pensadores escolásticos, así como de las disputas y controversias teóricas de sus contemporáneos -sobre todo españoles- acerca de determinados conceptos filosóficos y teológicos centrales, como, por ejemplo, la noción de forma de corporeidad.

De igual modo, destacamos la figura de Aristóteles que se presenta a lo largo del curso, pues, por una parte, se corresponde con la del Filósofo de la tradición clásica y, por otra, -como es propio en la época- sus doctrinas se ven matizadas con ideas católicas. También desde un punto de vista filosófico, fray Juan de Fuica se nos muestra como un fiel seguidor de las doctrinas del Doctor Sutil Duns Escoto y, por ello, constituye un autor ejemplar de la corriente escotista en Chile

En un sentido aún más preciso, si bien en el curso apreciamos errores ortográficos y gramaticales que no garantizarían una revisión cuidadosa de los textos, nos inclinamos a pensar que el libro que reúne los comentarios del trienio 1687-1689 podría ser el esfuerzo del fraile por responder a las demandas internas de la orden de unificar las materias requeridas por los estudiantes de Artes. De este modo, el libro podría constituir un esbozo para un eventual Manual de estudios de la provincia chilena.

En todo caso, y de no ser así, el curso de fray Juan de Fuica constituye inapelablemente un testimonio único de la enseñanza de la filosofía franciscana de la época. Su estudio detallado y nuestra traducción al castellano lo convierten en una herramienta de investigación filosófica e histórica que permite visibilizar y enriquecer el patrimonio filosófico colonial del país y, en consecuencia, llenar una gran laguna en la historia de la filosofía chilena. 


\section{REFERENCIAS}

-Actas del Definitorio. Archivo de la Provincia Franciscana (Vol. III, 1714-1735), Santiago de Chile.

-Aravena Zamora, A. (2015). Manuscritos filosóficos coloniales conservados en el Archivo Nacional Histórico de Santiago de Chile. Revista Española de Filosofia Medieval (22), 289-305.

-Aristóteles (1970). Metafísica. (Edición trilingüe por V. García Yebra). Madrid: Gredos.

-Aristóteles (1987). Tratados breves de historia natural. (Introducción, traducción y notas por A. B. Pajares). Madrid: Gredos.

-Aristóteles (1992). Investigación sobre los animales. (Introducción de Carlos García Gual; traducción y notas de J. Palli). Madrid: Gredos.

-Aristóteles (1994). Reproducción de los animales. (Introducción, traducción y notas de E. Sánchez). Madrid: Gredos.

-Aristóteles (1999). Acerca del alma. (Introducción, traducción y notas de T. Calvo). Madrid: Gredos.

-Aristóteles (2000). Marcha de los animales. (Introducciones, traducciones y notas de E. Jiménez y A. Alonso). Madrid: Gredos.

-Aristóteles (2000). Partes de los animales. (Introducciones, traducciones y notas de E. Jiménez y A. Alonso). Madrid: Gredos.

-Aristóteles (2007). Física. (Introducción, traducción y notas de Guillermo R. de Echandía). Madrid: Gredos.

-Cazanova, F. (1998). Historia de la Recoleta I. Santiago de Chile: Publicaciones del Archivo Franciscano.

-De Fuica, J. (1687). Commentaria phylosophica ad mentem Doctoris Subtilissimi Patris Fratris Joannis Duns Scoti Sacratissimi Ordinis Minorum et Theologorum Principis. Archivo de la Provincia Franciscana, Santiago de Chile.

-De Fuica, J. (1689). Commentaria in tres libros De anima ad mentem nostri Subtilis Doctoris Duns Scoti, Theologorum Principis. Archivo de la Provincia Franciscana, Santiago de Chile.

-Espejo, J. L. (1917). Nobiliario de la Antigua Capitania General de Chile. Santiago de Chile: Imprenta Universitaria.

-Guerrero Troncoso, H. (2014). La escuela escotista en el Chile colonial. Alonso Briceño y Juan de Fuica. Revista Chilena de Estudios Medievales (6), 29-42.

-Herrero, V. (1965). Introducción al estudio de la filología latina. Madrid: Gredos.

-Informes de Novicios (1603-1739). Archivo de la Provincia Franciscana, Santiago de Chile.

-Inventario Biblioteca Casa Grande 1799. Archivo de la Provincia Franciscana, Santiago de Chile.

-Iturriaga, R. (1990a). El Colegio San Diego de Alcalá. Santiago de Chile: Publicaciones del Archivo Franciscano.

-Iturriaga, R. (1990b). El Escotismo en Chile. Anuario de Historia de la Iglesia en Chile (8), 37-58. 
-Iturriaga, R. (2001). Tablas Capitulares de la Provincia Franciscana (XVII). Santiago de Chile: Publicaciones del Archivo Franciscano.

-Medina, J. T. (1905). La Instrucción Pública en Chile desde sus orígenes hasta la fundación de la Universidad de San Felipe (2 Vols.). Santiago de Chile: Imprenta Elzeveriana.

-Nava, M. (1997). Los Cursus Philosophici de Suárez y Urbina. El latín colonial en Venezuela y dos manuscritos filosóficos. Cuadernos de Filología Clásica. Estudios latinos (12), 179-192.

-Palmer, L. (1974). Introducción al Latín. Barcelona: Editorial Planeta.

-Ramírez, H. (1992). Fuentes para la historia franciscana II. Libros Becerros de Actas y Decretos del Venerable Definitorio de la Provincia Franciscana de la Santísima Trinidad de Chile. Índice de Materias y Extractos. Siglo XVIII (1700-1734). Santiago de Chile: Publicaciones del Archivo Franciscano.

-Ramírez, H. (1993). Fuentes para la historia franciscana IV. Libros Becerros de Actas y Decretos del Venerable Definitorio de la Provincia Franciscana de la Santísima Trinidad de Chile. Índice de Materias y Extractos. Siglo XVIII (1765-1799). Santiago de Chile: Publicaciones del Archivo Franciscano.

-Saranyana, J. I. (2011). La Filosofía Medieval. Desde sus orígenes patrísticos hasta la escolástica barroca. Navarra: Ediciones Universidad de Navarra S. A.

-Scotus, I. (2006). Quaestiones super secundum et tertium De anima. Washington D. C.: The Catholic University of America Press; St. Bonaventure, N. Y.: The Franciscan Institute.

-Tovar, A. (1970). Lo medieval en la conquista y otros ensayos americanos. Madrid: Seminarios y Ediciones.

-Väänänen, V. (2003). Introducción al Latín vulgar. Madrid: Gredos.

Sumario: 1. Nota biográfica; 2. Características generales de los Comentarios Acerca del alma; 3. Características del lenguaje en los Comentarios Acerca del alma; 4. Estructura de los Comentarios Acerca del alma; 5. Método de enseñanza; 6. Contenidos ad mentem Scoti; Conclusiones; Referencias. 